\title{
BMJ Open Aspiration risk in relation to Glasgow Coma Scale score and clinical parameters in patients with severe acute alcohol intoxication: a single-centre, retrospective study
}

\author{
Michael Conzelmann, ${ }^{1,2}$ Anne Hoidis, ${ }^{3}$ Thomas Bruckner, ${ }^{4}$ Erik Popp, ${ }^{5}$ \\ Ronald Koschny (D) ${ }^{3}$
}

To cite: Conzelmann M, Hoidis A, Bruckner T, et al. Aspiration risk in relation to Glasgow Coma Scale score and clinical parameters in patients with severe acute alcohol intoxication: a single-centre, retrospective study. BMJ Open 2021;11:e053619. doi:10.1136/ bmjopen-2021-053619

- Prepublication history for this paper is available online. To view these files, please visit the journal online (http://dx.doi. org/10.1136/bmjopen-2021053619).

Received 20 May 2021

Accepted 20 September 2021

A) Check for updates

(C) Author(s) (or their employer(s)) 2021. Re-use permitted under CC BY-NC. No commercial re-use. See rights and permissions. Published by BMJ.

For numbered affiliations see end of article.

Correspondence to Dr Ronald Koschny; ronald.koschny@med.uniheidelberg.de

\section{ABSTRACT}

Objectives In alcohol intoxicated patients, the decision for or against airway protection can be challenging and is often based on the Glasgow Coma Scale (GCS). Primary aim of this study was to analyse the aspiration risk in relation to the GCS score and clinical parameters in patients with severe acute alcohol monointoxication. Secondary aim was the association between the blood alcohol level and the GCS score.

Setting Single-centre, retrospective study of alcoholised patients admitted to a German intensive care unit between 2006 and 2020.

Participants A total of $n=411$ admissions were eligible for our analysis.

Clinical measures and analysis The following data were extracted: age, gender, admission time, blood alcohol level, blood glucose level, initial GCS score, GCS score at admission, vital signs, clinical signs of aspiration and airway management measures. The empirical distribution of continuous and categorical data was calculated. Binary multivariable logistic regression analysis was used to identify possible risk factors for aspiration.

Results The mean age was 35 years. $72 \%(n=294)$ of the admissions were male. The blood alcohol level (mean $2.7 \mathrm{~g} /$ $\mathrm{L} \pm 1.0$, maximum $5.9 \mathrm{~g} / \mathrm{L}$ ) did not correlate with the GCS score but with the age of the patient. In univariate analysis, the aspiration risk correlated with blood alcohol level, age, GCS score, oxygen saturation, respiratory rate and blood glucose level and was significantly higher in male patients, on vomiting, and in patients requiring airway measures. Aspiration rate was $45 \%(n=10)$ in patients without vs $6 \%(\mathrm{n}=3)$ in patients with preserved protective reflexes $(p=0.0001)$. In the multivariate analysis, only age and GCS score were significantly associated with the risk of aspiration. Conclusion Although in this single-centre, retrospective study the aspiration rate in severe acute alcohol monointoxicated patients correlates with GCS and protective reflexes, the decision for endotracheal intubation might rather be based on the presence of different risk factors for aspiration.

\section{INTRODUCTION}

Patients with acute ethanol intoxication frequently require medical treatment,
Strengths and limitations of this study

- We provide an analysis of the so far largest homogeneous cohort of alcohol monointoxicated nontraumatic intensive care unit patients for risk factors of aspiration.

- Since the aspiration pneumonia could have developed after the discharge of the patient from the hospital in cases with short-time in-hospital care, we might have missed some aspiration events.

- Since a minority of patients were admitted to the hospital more than once, we analysed admissions instead of patients as single events.

- Within our cohort of limited sample size we identified risk factors for aspiration which could help to guide clinical diagnostic and therapeutic workup.

- However, due to the retrospective nature of this single-centre study, we cannot provide direct clinical recommendations.

observation and diagnostics by paramedics, emergency physicians, emergency departments as well as intensive care units (ICU). ${ }^{1}$ Up to $12 \%$ of the attendances at the emergency department of an innercity hospital in the UK were alcohol related, mostly due to acute intoxication. ${ }^{2}$ In Ontario, Canada, $5.1 \%$ of visits to the emergency department were attributable to alcohol use. ${ }^{3}$ Besides respiratory depression, an elevated risk of aspiration due to impaired consciousness after alcohol consumption can cause lifethreatening complications. ${ }^{4}{ }^{5}$ In patients with trauma with impaired consciousness, a Glasgow Coma Scale (GCS) score of 8 or less is widely accepted as an indication for an airway protection by endotracheal intubation. ${ }^{6}$ Although alcohol intoxicated patients often present with impaired consciousness and a GCS score of less than 8, the reported 
intubation rate of $0 \%-2.3 \%$ is low compared with the overall intubation rate of $3 \%-5 \%$ in prehospital emergencies. ${ }^{7-11}$ The clinical benefit of intubating intoxicated patients with a GCS score $\leq 8$ in order to prevent aspiration is still controversially discussed. ${ }^{89-14}$ Apart from adverse events like hypotension and cardiac arrest, prehospital intubation bears a risk of approx. $8 \%$ for the development of an intubation-related aspiration pneumonia. ${ }^{15}$ Therefore, the risk-benefit ratio of prehospital invasive airway measures needs to be carefully considered. Differences of aspiration and intubation rates between mixed intoxications and alcohol monointoxications suggest that these clinical conditions might not be comparable regarding the necessity for airway protection. In contrast to mixed intoxication, data regarding airway impairment in acute alcohol monointoxication are very scarce.

The primary aim of this study was to search for risk factors for aspiration in adolescent and adult atraumatic patients who required admission to our ICU due to severe acute alcohol monointoxication. As a secondary aim, we analysed the association between the blood alcohol level and the GCS score.

\section{MATERIAL AND METHODS Study design and population}

For this retrospective study, all patients who had been admitted to the ICU of the Department of Gastroenterology at the University Hospital of Heidelberg between January 2006 and December 2020 were screened for acute mono-intoxication with alcohol (ethanol). Mixed intoxication was assumed when reported by the patient or relatives or in case of indicative prehospital scenarios (empty blisters, visible injection signs) or positive toxicology screening on admission to the hospital (see the 'Measurements' section). These patients were excluded from the study. Alcohol intoxication was defined as impaired consciousness due to a blood alcohol level $\geq 0.8 \mathrm{~g} / \mathrm{L}$, which is the legal definition for alcohol intoxication in many countries. ${ }^{16}$ Patients with missing data regarding blood alcohol level or GCS score were excluded, as well as patients with severe comorbidities or medical conditions interfering with consciousness, airway situation, aspiration risk or breathing rate. Details of excluded patients are given in figure 1. Deep therapeutic sedation was defined as sedation by the emergency physician resulting in an iatrogenic GCS score $\leq 8$. Severe hypothermia was defined by a core temperature $\leq 34^{\circ} \mathrm{C}$. Hypoglycaemic was defined as any blood glucose level $<65 \mathrm{mg} / \mathrm{dL}$ as the lower level of normal regarding our standard point-of-care-testing (POCT) devices. Concomitant use of common medication at therapeutic doses was permitted. The following data were extracted from the medical records: age, gender, admission time, blood alcohol level, blood glucose level, initial GCS score (first GCS), GCS score at admission to the hospital (second GCS), initial (prehospital) vital signs (systolic blood pressure, heart rate, breathing rate, peripheral capillary oxygen saturation $\left.\left(\mathrm{SpO}_{2}\right)\right)$, clinical and
458 admissions with acute alcohol intoxication

\section{Missing data}

21 No blood alcohol level measured

5 No GCS available

Severe interfering medical condition

3 Deep sedation

4 Severe hypothermia $\left(<34^{\circ} \mathrm{C}\right)$

4 Epileptic seizure

2 Lactic/ketoacidosis, hyperosmotic coma

1 Anaphylactic shock

2 Hepatic encephalopathia

5 Hypoglycemia

1 Resuscitation

2 Severe hematemesis

411 admissions for analysis

Figure 1 Composition of the study cohort. From the initial cohort of 458 atraumatic patients with acute alcohol monointoxication, 47 admissions were excluded due to missing data or severe interfering medical conditions, resulting in 411 admissions eligible for the final analysis. In three cases, two different exclusion criteria were present. GCS, Glasgow Coma Scale.

prehospital signs of aspiration and airway management measures. When patients were prehospitally intubated, only the first GCS score before intubation was recorded, since the second GCS score was narcosis-induced (usually GCS score $=3$ ). Aspiration was rated positive if proven by bronchoscopy or if clinical suspicion was supported by at least one of the following factors: coughing up aspirate, coarse crackles on auscultation, new opacities on chest $\mathrm{X}$-ray, development of fever or laboratory signs of inflammation ( $\mathrm{C}$ reactive protein, leukocytosis) without other overt reasons. Patients without clinical signs of aspiration or normal bronchoscopy were rated negative.

\section{Measurements}

Except for prehospital measurements of blood glucose levels by POCT according to the emergency medical service, blood samples were obtained immediately after the patient's admission to our hospital for venous blood gas analysis (RAPIDLab 1200, Siemens Healthcare Diagnostics, Eschborn, Germany), measurement of blood alcohol level and standard laboratory tests including glucose. When indicated by the patient's history or clinical data, a qualitative urine toxicology screen (Triage 8 Drugs of Abuse Panel, Alere Diagnostics, Cologne, Germany) was performed to exclude mixed intoxications. This test detects the following components: amphetamine, barbiturates, benzodiazepines, cocaine, methadone, opiates, tetrahydrocannabinol, and tricyclic antidepressants. Due to the low specificity, sensitivity and clinical benefit, urine toxicology test was not performed on a regular basis. ${ }^{17}$

\section{Statistical analysis}

Data entry was performed with help of Microsoft Excel (V.14.0), for the statistical analysis SAS V.9.4 WIN (SAS Institute) was used. The empirical distribution of continuous data was described with mean, $\mathrm{SD}$ and range, in case of categorical data with absolute and relative frequencies. 
Table 1 Baseline characteristics of the study population at admission

\begin{tabular}{|c|c|}
\hline Total no of admissions & 411 \\
\hline No of different patients & 360 \\
\hline $\begin{array}{l}\text { Patients with more than one } \\
\text { admission }\end{array}$ & 33 \\
\hline Patients with two admissions & 21 \\
\hline Patients with three admissions & 7 \\
\hline Patients with four admissions & 4 \\
\hline Patients with five admissions & 1 \\
\hline Gender, males/females (\%) & $294 / 117(72 \% / 28 \%)$ \\
\hline Age, mean $\pm S D$, (range) (years) & $35 \pm 15(15-74)$ \\
\hline $\begin{array}{l}\text { Blood alcohol level, mean } \pm S D \text {, } \\
\text { (range) }(\mathrm{g} / \mathrm{L})\end{array}$ & $2.7 \pm 1.0(0.9-5.9)$ \\
\hline $\begin{array}{l}\text { Peripheral oxygen saturation, } \\
\text { mean } \pm \text { SD, (range) (\%) }\end{array}$ & $96 \pm 6(47-100)$ \\
\hline Heart rate, mean \pm SD (range) (bpm) & $92 \pm 20(35-180)$ \\
\hline $\begin{array}{l}\text { Systolic blood pressure, mean } \\
\pm \mathrm{SD} \text { (range) }(\mathrm{mm} \mathrm{Hg})\end{array}$ & $121 \pm 22(70-200)$ \\
\hline $\begin{array}{l}\text { Respiratory rate, mean } \pm \text { SD (range) } \\
(1 / \text { min) }\end{array}$ & $15 \pm 5(0-35)$ \\
\hline
\end{tabular}

Spearman's correlation coefficient was calculated to describe associations between blood alcohol level and laboratory values. Possible differences between patients with and without aspiration were tested with t-test for continuous data and $\chi^{2}$-tests for categorical data. Binary multivariable logistic regression analysis was used to find possible risk factors for aspiration. Statistical graphics were used to visualise the findings.

\section{Patient and public involvement}

No patient involved.

\section{RESULTS}

A total of $n=411$ admissions to our ICU for acute alcohol monointoxication comprising $\mathrm{n}=360$ different patients were eligible for our analysis. The baseline characteristics of the enrolled patients and their vital parameters are listed in table 1.

The mean blood alcohol level did not significantly differ between male $(2.7 \pm 1.0 \mathrm{~g} / \mathrm{L})$ and female $(2.5 \pm 1.1 \mathrm{~g} / \mathrm{L})$ patients $(\mathrm{p}=0.132)$. The maximum blood alcohol level was $5.9 \mathrm{~g} / \mathrm{L}$ and $5.9 \mathrm{~g} / \mathrm{L}$ in male and female patients, respectively. In figure 2 , the blood alcohol levels are shown according to age and gender. The blood alcohol level strongly correlated with patient's age $(r=0.43$, $\mathrm{p}<0.0001)$ in the total population, as well as in male $(\mathrm{r}=0.46, \mathrm{p}<0.0001)$ and female patients $(\mathrm{r}=0.33, \mathrm{p}=0.003)$.

In order to analyse the fluctuating consciousness in acute alcohol intoxication, we compared the first GCS score of the patient on arrival of the emergency team with the second GCS score at admission to the hospital approximately 30-60 min later. The median GCS score

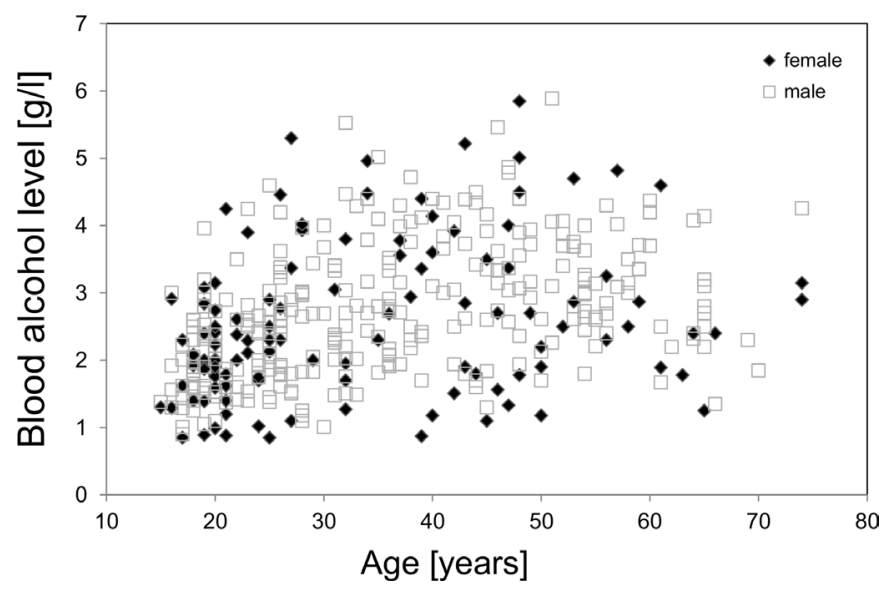

Figure 2 Blood alcohol levels at admission are plotted as a function of age, separately for $n=294$ admission of male ( $\square$ ) and $n=117$ admissions of female $(\diamond)$ patients.

improved from 10 to 13 between prehospital presentation and admission to the ICU. Figure 3 visualises the strong correlation between the first and second GCS score $(\mathrm{r}=0.77, \mathrm{p}<0.0001)$. Dots on the diagonal line correspond to patients with identical first and second GCS scores. We considered a change of \pm 3 GCS points ( $\triangle \mathrm{GCS}$ ) as clinically relevant. Most patients $(\mathrm{n}=258,79 \%)$ did not show a relevant change of the GCS score $(-2 \leq \Delta \mathrm{GCS} \leq+2)$. While $\mathrm{n}=61$ admissions $(19 \%)$ demonstrated an improvement of their consciousness level during their transport to the hospital ( $\Delta$ GCS score $\geq+3$ ), only $n=10$ patients $(3 \%)$ showed a relevant deterioration ( $\triangle$ GCS score $\leq-3)$.

To rule out any bias due to mixed GCS records (ie, pooled first and second GCS scores), all following analyses regarding GCS scores were performed with the first GCS score only. The median first GCS score did not differ between male and female patients (10 vs $10, \mathrm{p}=0.864)$. Blood alcohol levels did neither correlate with the initial GCS score in the general population $(\mathrm{r}=-0.05, \mathrm{p}=0.279)$, nor for male $(\mathrm{r}=-0.05, \mathrm{p}=0.331)$ or female $(\mathrm{r}=-0.04$, $\mathrm{p}=0.673$ ) patients. Nevertheless, very high blood alcohol levels $(>5 \mathrm{~g} / \mathrm{L})$ were measured only in patients with a first GCS score $\leq 11$ (figure 4 ). The highest blood alcohol levels of 5.9 and $5.9 \mathrm{~g} / \mathrm{L}$ were found in 2 patients with a GCS score of 3 and 8, respectively.

Within the total population of $n=411$ patients, aspiration was found in $n=21(5 \%)$. Aspiration was diagnosed by a positive bronchoscopy in $n=5(24 \%)$ of these patients. In the remaining $n=16$ patients, diagnosis of aspiration was based on the presence of at least one of the following criteria: coarse crackles on auscultation $(n=9)$, new opacities on chest X-ray $(n=6)$, development of fever or laboratory signs of inflammation $(n=6)$. In order to identify risk factors for aspiration in alcohol intoxicated patients, we compared the cohorts with and without aspiration regarding demographic characteristics, vital signs, blood alcohol level, blood glucose level and airway management. In univariate analysis of continuous risk factors for aspiration, patients with aspiration were significantly older (mean age 47 vs 35 years), had a higher blood 


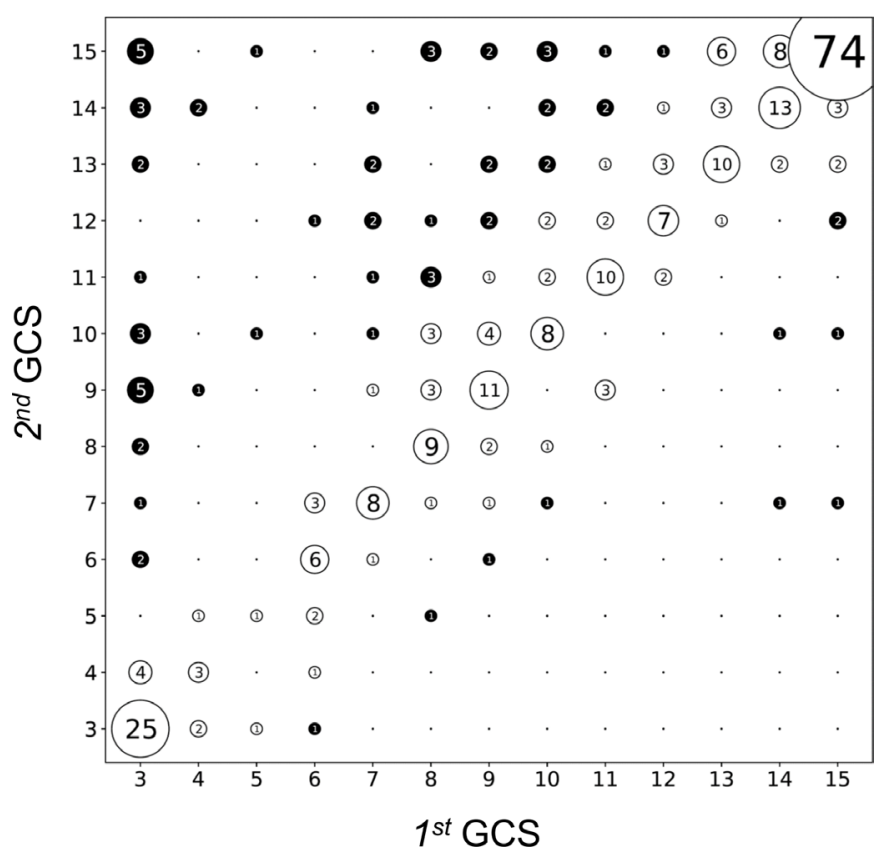

Figure 3 Correlation between the first GCS score at prehospital presentation and the second GCS score at hospital admission ( $n=336$ complete data sets). The diagonal represents patients with no change in GCS score during their prehospital treatment. The number of patients is inscribed within each dot and reflected by the dot size. A change of \pm 2 points between first and second GCS score was considered clinically irrelevant (unfilled circles). Patients with changes of their GCS score of 3 or more points are considered clinically relevant (filled circles). GCS, Glasgow Coma Scale.

alcohol level (mean 3.4 vs $2.6 \mathrm{~g} / \mathrm{L}$ ), a lower first GCS score (median 3 vs 11), a lower $\left(\mathrm{SpO}_{2}\right.$, mean 90 vs $96 \%$ ), a lower respiration rate (mean $13 / \mathrm{min}$ vs $15 / \mathrm{min}$ ) and a higher blood glucose level (139 vs $109 \mathrm{mg} / \mathrm{dL}$ ) (table 2).

Furthermore, univariate results of binary risk factors revealed a significantly higher risk for aspiration for male patients, patients with documented airway measures as listed in table 3.

Intubated patients showed a significantly higher aspiration rate than patient's without intubation $(56 \%$ vs

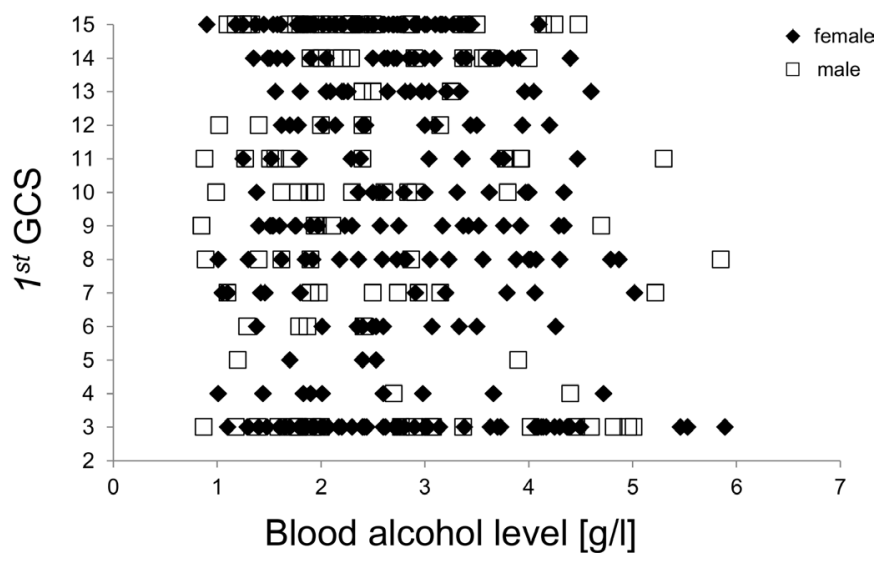

Figure 4 Correlation between first GCS score and blood alcohol level for male $(\square)$ and female $(\diamond)$ patients. GCS, Glasgow Coma Scale.
$2 \%$ ). Since many emergency physicians base their decision for intubation in patients with a GCS score $\leq 8$ on the presence or absence of the swallowing and gag reflex, the presence of these protective reflexes was correlated with the risk of aspiration. A total of $\mathrm{n}=152$ patients had a first GCS score $\leq 8$. Data regarding protective reflexes were available in $n=74(49 \%)$ of these patients. Protective reflexes in patients with GCS score $\leq 8$ were present in $\mathrm{n}=52(70 \%)$, but absent in $\mathrm{n}=22(30 \%)$. The absence of protective reflexes was significantly associated with a higher risk of aspiration: $45 \%$ aspiration rate in patients without vs $6 \%$ in patients with protective reflexes ( $\mathrm{p}=0.0001$, table 3$)$.

On multivariate analysis of the risk factors gender, age, blood alcohol level, first GCS score, and $\mathrm{SpO}_{2}$, only age (OR 1.06) and GCS score (OR 0.71) significantly correlated with the risk of aspiration (table 4).

Due to the low number of complete data sets, presence of protective reflexes could not be included in the multivariate analysis. The difference of age and GCS score between aspirated and non-aspirated patients is visualised as box plots in figure 5A,B. However, a GCS score=3 had a low sensitivity (60\%) and a moderate specificity (83\%) for aspiration, with a positive predictive value (PPV) of only $16 \%$ and very high negative predictive value (NPV) of $98 \%$. Since information on the preservation of protective airway reflexes in these patients were rather scarce, the PPV and NPV were calculated for a GCS score $=3$, irrespective of the gag reflex.

\section{DISCUSSION}

Acute alcohol intoxication constitutes a frequent medical problem with a considerable socioeconomic and healthcare system burden. The demographic analysis of our cohort shows a predominance of young male patients, which is comparable to other demographic studies. ${ }^{18} 19$ However, our ICU cohort showed a younger age distribution than another retrospectively analysed cohort of patients admitted to an emergency department. ${ }^{1}$ With a mean alcohol level of $2.7 \mathrm{~g} / \mathrm{L}$, our cohort showed higher blood alcohol levels than many other studies,${ }^{20-23}$ which might be due to the selection of ICU patients. In contrast to Vereslt $e t a l,{ }^{1}$ a higher age was associated with a higher blood alcohol level in our cohort.

Since the short period of prehospital care of alcoholised patients impedes a relevant alcohol degradation, one would expect-if at all-a deterioration of the GCS between the first patient contact and the admission to the hospital due to an ongoing alcohol resorption in the alimentary tract. However, $19 \%$ of our patients showed an improvement of more than 2 GCS score points during their prehospital care, but only $3 \%$ of patients showed a relevant deterioration. Overall, we found a strong correlation between the first and second GCS score. The prehospital blood alcohol level is not routinely available to the emergency team. Therefore, we can neither provide data on its kinetics, nor does the clinical decision rely on these 
Table 2 Univariate analysis of continuous risk factors for aspiration

\begin{tabular}{|c|c|c|c|c|c|}
\hline Parameter & $\begin{array}{l}\text { Patients without } \\
\text { aspiration } \\
\text { Mean士SD (range) }\end{array}$ & $\begin{array}{l}\text { Eligible } \\
\text { patients }\end{array}$ & $\begin{array}{l}\text { Patients with aspiration } \\
\text { Mean } \pm \text { SD (range) }\end{array}$ & $\begin{array}{l}\text { Eligible } \\
\text { patients }\end{array}$ & $P$ value \\
\hline Age (years) & $34.6 \pm 14.5(15-74)$ & 390 & $47.4 \pm 9.3(32-65)$ & 21 & $<0.0001$ \\
\hline Blood alcohol level (g/L) & $2.6 \pm 1.0(0.9-5.9)$ & 390 & $3.4 \pm 1.3(1.7-5.5)$ & 21 & 0.017 \\
\hline Initial GCS score & $11($ median $) \pm 4(3-15)$ & 378 & 3 (median) $\pm 2(3-9)$ & 20 & $<0.0001$ \\
\hline Heart rate (bpm) & $92 \pm 20(35-180)$ & 377 & $89 \pm 20(50-120)$ & 21 & 0.580 \\
\hline Respiratory rate (1/min) & $15 \pm 5(0-35)$ & 302 & $13 \pm 3(8-18)$ & 19 & 0.014 \\
\hline Blood glucose level (mg/dL) & $109 \pm 40(65-487)$ & 388 & $139 \pm 60(72-335)$ & 21 & 0.028 \\
\hline
\end{tabular}

GCS, Glasgow Coma Scale; $\mathrm{SpO}_{2}$, peripheral oxygen saturation.

data. The GCS score of head injured trauma patients with additional alcohol intoxication also improved between prehospital care and the emergency department. ${ }^{24}$ This implies that the measurement time point of the GCS score during the prehospital care should be exactly defined and pooling of GCS data from different phases of care should be avoided. Slight changes in GCS score might not necessarily reflect a clinically relevant change of consciousness level of alcoholised patients. We, therefore, considered only an arbitrarily defined $\Delta$ GCS of $\geq 3$ as clinically relevant.

Most data on the influence of alcohol on the GCS score were derived from trauma patients. Some studies showed a correlation between blood alcohol level and
GCS score, ${ }^{25}$ while others did not. ${ }^{26-28}$ In our study on non-traumatic alcoholised patients, the blood alcohol level did not correlate with the GCS score even at a considerably high mean blood alcohol level of $2.7 \mathrm{~g} / \mathrm{L}$.In adolescent patients (13-17 years of age) with rather mild alcohol intoxication (mean $1.6 \mathrm{~g} / \mathrm{L}$ ), Mick et $a l^{20}$ found a significant correlation between the blood alcohol level and the GCS score. One might speculate that adolescents and younger adults have not yet undergone habituation to regular alcohol consumption. However, even in the youngest subgroup (15-25 years) of our study, there was no significant correlation between blood alcohol level and GCS score ( $\mathrm{n}=136$ patients, mean blood alcohol level $2.1 \mathrm{~g} / \mathrm{L}$, median GCS score 10, $\mathrm{p}=0.061)$.

Table 3 Univariate analysis of binary risk factors for aspiration

\begin{tabular}{|c|c|c|c|c|c|}
\hline Parameter & Manifestation & $\begin{array}{l}\text { Patients without } \\
\text { aspiration (\%) (n) }\end{array}$ & $\begin{array}{l}\text { Patients with } \\
\text { aspiration (\%) (n) }\end{array}$ & $\begin{array}{l}\text { Evaluable patients } \\
\text { (n) }\end{array}$ & $P$ value \\
\hline Gender & Male & $93.5(275)$ & $6.5(19)$ & 294 & 0.048 \\
\hline \multirow[t]{2}{*}{ Vomiting } & No & $96.4(317)$ & 3.7 (12) & 329 & 0.017 \\
\hline & Yes & $89.9(71)$ & $10.1(8)$ & 79 & \\
\hline \multirow[t]{2}{*}{ Guedel tube application } & No & 95.5 (382) & $4.5(18)$ & 400 & 0.0003 \\
\hline & Yes & $70.0(7)$ & $30.0(3)$ & 10 & \\
\hline \multirow[t]{2}{*}{ Mask ventilation } & No & $95.8(383)$ & $4.2(17)$ & 400 & $<0.0001$ \\
\hline & Yes & $60.0(6)$ & $40.0(4)$ & 10 & \\
\hline Secretion suction & Yes & $46.1(6)$ & $53.9(7)$ & 13 & \\
\hline \multirow[t]{2}{*}{ Intubation } & No & $98.4(377)$ & $1.6(7)$ & 384 & $<0.0001$ \\
\hline & Yes & $44.4(12)$ & $55.6(15)$ & 27 & \\
\hline
\end{tabular}

GCS, Glasgow Coma Scale. 
Table 4 OR estimates in multivariate analysis of risk factors for aspiration

\begin{tabular}{lllc}
\hline Risk factor & OR & 95\% Cls & P value \\
\hline Gender (male vs female) & 3.29 & 0.67 to 16.03 & 0.141 \\
Age & 1.06 & 1.02 to 1.10 & 0.005 \\
Blood alcohol level & 1.26 & 0.80 to 2.00 & 0.320 \\
First GCS score & 0.71 & 0.60 to 0.84 & $<0.0001$ \\
Oxygen saturation & 0.98 & 0.93 to 1.03 & 0.397 \\
\hline
\end{tabular}

GCS, Glasgow Coma Scale.

One of the most challenging clinical problems in unconscious alcohol-intoxicated patients is the decision for or against airway protection by intubation. Many studies were performed in heterogeneous cohorts of mixed intoxication, ${ }^{79}$ 29-31 in patients with trauma ${ }^{832}$ or without any data on the risk of aspiration. ${ }^{829}$ While some authors and recommendations refer to a GCS score $\leq 8$ as an indication for intubation in alcohol intoxicated patients, the association of a low GCS score with a higher risk of aspiration has not been sufficiently substantiated in these patients. In their prospective observational study, Duncan et $a l^{7}$ did not find a higher rate of aspiration in patients with a GCS score $\leq 8$. However, only $n=22$ of 73 patients had alcohol monointoxication and only $n=12$ patients of their entire cohort demonstrated a GCS score $\leq 8$. Comparing $\mathrm{n}=12$ intubated (mean GCS score 5.9) with $\mathrm{n}=14$ not-intubated (mean GCS score 5.5) patients with mixed intoxication, Donald et a $\ell^{\ominus}$ did not detect a difference in laboratory or physiological parameters. However, the aspiration rate was not analysed. None of the intubated patients had an alcohol intoxication. In patients with a mixed intoxication, the risk of aspiration pneumonia did not significantly differ between patients with a GCS score $\leq 8$ vs a GCS score $>8$. $^{13}$ In another prospective study on $n=224$ drug-intoxicated patients, there was no correlation between the GCS score and the risk of aspiration. ${ }^{31}$ A GCS score $\leq 8$ was not considered as essential for an increased risk of aspiration. However, the aspiration rate in that drug-intoxicated cohort was very high (29\%) compared with our study $(5 \%)$. This indicates that mixed intoxication and alcohol monointoxication might not be comparable regarding the risk of aspiration.

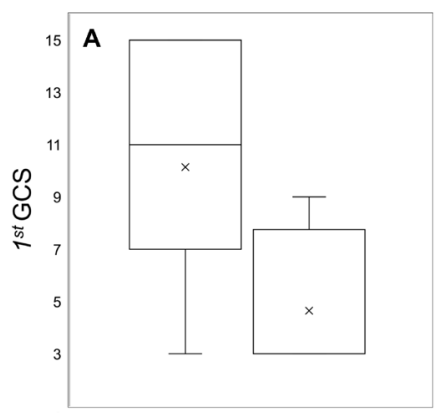

w/o aspiration with aspiration

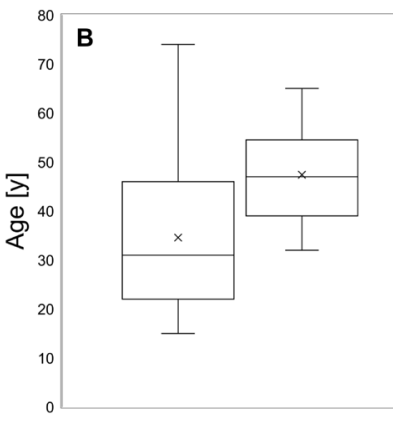

w/o aspiration with aspiration
Figure 5 Distribution of the first GCS score (A) and age (B) for patients without aspiration versus proven aspiration, presented as box plots. GCS, Glasgow Coma Scale.
In our study on non-traumatic alcohol-monointoxicated patients, we found a strong correlation between the GCS score and the risk of aspiration, even in a multivariate regression model. However, $n=133$ of the 152 patients $(88 \%)$ with GCS score $\leq 8$ did not aspirate. Thus, even for a GCS score=3 the PPV is too low $(16 \%)$ to guide the decision for intubation. However, Sauter et al described that a GCS score $\leq 8$ was the main reason for emergency teams to decide for intubation in intoxicated patients. In our cohort, emergency physicians-according to their emergency protocols-made a more differentiated decision for intubation based on GCS score, presence of the gag reflex, vomiting and the suspicion of aspiration.

An alternative parameter to estimate the risk for aspiration is the presence of the gag or cough reflex. However, in a very small cohort of patients with pharmacologically induced coma the cough reflex did not correlate with the GCS score, as $n=4$ of 12 patients $(33 \%)$ with a GCS score $=3$ had an unimpaired cough reflex. On the other hand, three of five patients $(60 \%)$ with a GCS score $=8$ had an impaired cough reflex. ${ }^{29}$ These data are supported by the detection of a depressed gag reflex in drug-intoxicated patients even at a GCS score $\geq 8 .{ }^{30}$ Of note, none of these studies has been performed in alcohol monointoxicated patients. In our study we could obtain information on the gag or cough reflex in $n=74$ patients. The absence of protective airway reflexes did significantly correlate with an increased risk of aspiration in a univariate analysis (table 3). Furthermore, all airway measures significantly correlated with the rate of aspiration (table 3). For instance, the necessity of secretion suction or intubation (on the discretion of the emergency physician) were each associated with an aspiration rate of $>50 \%$. Our data are in line with a smaller retrospective study on $n=155$ patients with mixed intoxication in which patients with reduced GCS scores or an impaired gag reflex had a higher risk for an aspiration pneumonitis. ${ }^{12}$ An absent or reduced gag reflex was found in $96 \%$ of their patients with aspiration. However, the high aspiration rate of $15 \%$ in their cohort of mixed intoxication might be related to the application of gastric lavage and charcoal administration which is not applied in alcohol monointoxication. Our study impressively shows that the execution of some airway measures (eg, oxygen supply) or encountered vomiting indicated only a low risk of aspiration, while other measures (eg, mask ventilation, secretion suction, intubation) and the lack of protective airway reflexes indicate a 
high aspiration incidence in these patients. This would imply a thorough diagnostic (eg, X-ray, bronchoscopy) or therapeutic (eg, antibiotic treatment) workup in these high-risk patients on ICU admission. However, a GCS score $\leq 8$ alone should not warp the emergency physician into endotracheal intubation.

Although herewith we present-to the best of our knowledge-the most comprehensive analysis of the aspiration risk in alcohol monointoxicated patients, our study has some limitations. Due the retrospective nature of our study, we cannot provide direct clinical recommendations. Since protective airway reflexes were evaluated by the emergency team only in a subset of patients, there might be a bias towards reporting rather impaired than normal reflexes. However, since both preserved and impaired protective reflexes were listed as the reason against and in favour of intubation, respectively, we could not detect unilateral under-reporting or over-reporting. Since we focused on severely alcohol-intoxicated patients admitted to the ICU of our hospital, our finding might not be extrapolated to the general population with alcohol monointoxication in an emergency department.

\section{CONCLUSION}

In our retrospective study, we found that the blood alcohol level did correlate with the patient's age but not with the GCS score. However, both age and GCS score did correlate with the risk of aspiration. A GCS score $=3$ has a very low PPV for aspiration. We identified risk factors for aspiration in alcohol monointoxicated patients: Guedel tube application, mask ventilation, loss of protective airway reflexes, secretion suction, intubation. These patients might benefit from an aggressive diagnostic and therapeutic workup. Since only $6 \%$ of patients with preserved gag reflexes had aspirated, in this patient subgroup the risk of intubation might prevail its benefits.

\section{Author affiliations}

${ }^{1}$ Dept. of Human Toxicology \& Health Risk Assessment, BASF Corporate Health Management, Ludwigshafen am Rhein, Germany

${ }^{2}$ Postgraduate Study "Toxicology and Environmental Toxicology", Rudolf Boehm Institute of Pharmacology and Toxicology, Leipzig, Germany

${ }^{3}$ Dept. of Gastroenterology, University Hospital Heidelberg, Heidelberg, Germany

${ }^{4}$ Institute for Medical Biometry and Informatics, University Hospital Heidelberg, Heidelberg, Germany

${ }^{5}$ Dept. of Anaesthesiology, University Hospital Heidelberg, Heidelberg, Germany

Acknowledgements The authors like to thank Dr Thomas Koschny for assistance and support of graphical data representation.

Contributors MC, AH, EP and RK planned the study and performed the data acquisition. Statistical analysis was performed by TB. Manuscript writing and editing was performed by MC, AH, EP, TB and RK. The manuscript was submitted by MC.

Funding The authors have not declared a specific grant for this research from any funding agency in the public, commercial or not-for-profit sectors.

Competing interests None declared.

Patient and public involvement Patients and/or the public were not involved in the design, or conduct, or reporting, or dissemination plans of this research.

Patient consent for publication Not applicable.
Ethics approval The study was approved by the local ethics board of Heidelberg University (S-329/2013).

Provenance and peer review Not commissioned; externally peer reviewed.

Data availability statement Deidentified participant data are available from the corresponding autor on reasonable request.

Open access This is an open access article distributed in accordance with the Creative Commons Attribution Non Commercial (CC BY-NC 4.0) license, which permits others to distribute, remix, adapt, build upon this work non-commercially, and license their derivative works on different terms, provided the original work is properly cited, appropriate credit is given, any changes made indicated, and the use is non-commercial. See: http://creativecommons.org/licenses/by-nc/4.0/.

ORCID iD

Ronald Koschny http://orcid.org/0000-0003-2117-9137

\section{REFERENCES}

1 Verelst S, Moonen P-J, Desruelles D, et al. Emergency department visits due to alcohol intoxication: characteristics of patients and impact on the emergency room. Alcohol Alcohol 2012;47:433-8.

2 Pirmohamed M, Brown C, Owens L, et al. The burden of alcohol misuse on an inner-city General Hospital. QJM 2000;93:291-5.

3 Myran DT, Hsu AT, Smith G, et al. Rates of emergency department visits attributable to alcohol use in Ontario from 2003 to 2016: a retrospective population-level study. CMAJ 2019;191:E804-10.

4 Krumpe PE, Cummiskey JM, Lillington GA. Alcohol and the respiratory tract. Med Clin North Am 1984;68:201-19.

5 Vonghia L, Leggio L, Ferrulli A, et al. Acute alcohol intoxication. Eur J Intern Med 2008;19:561-7.

6 Gentleman D, Dearden M, Midgley S, et al. Guidelines for resuscitation and transfer of patients with serious head injury. BMJ 1993;307:547-52.

7 Duncan R, Thakore S. Decreased Glasgow coma scale score does not mandate endotracheal intubation in the emergency department. J Emerg Med 2009;37:451-5.

8 Sauter TC, Rönz K, Hirschi T, et al. Intubation in acute alcohol intoxications at the emergency department. Scand J Trauma Resusc Emerg Med 2020;28:11.

9 Donald C, Duncan R, Thakore S. Predictors of the need for rapid sequence intubation in the poisoned patient with reduced Glasgow coma score. Emerg Med J 2009;26:510-2.

10 Bernhard M, Bein B, Böttiger BW, et al. Handlungsempfehlung Zur prähospitalen Notfallnarkose beim Erwachsenen. Notfall + Rettungsmedizin 2015;18:395-412.

11 Luckscheiter A, Lohs T, Fischer M, et al. [Preclinical emergency anesthesia : A current state analysis from 2015-2017]. Anaesthesist 2019;68:270-81.

12 Eizadi-Mood N, Saghaei M, Alfred S, et al. Comparative evaluation of Glasgow coma score and Gag reflex in predicting aspiration pneumonitis in acute poisoning. J Crit Care 2009;24:470.e9-470.e15.

13 Montassier E, Le Conte P. Aspiration pneumonia and severe selfpoisoning: about the necessity of early airway management. $J$ Emerg Med 2012;43:122-3.

14 Orso D, Vetrugno L, Federici N, et al. Endotracheal intubation to reduce aspiration events in acutely comatose patients: a systematic review. Scand J Trauma Resusc Emerg Med 2020;28:116.

15 Driver BE, Klein LR, Schick AL, et al. The occurrence of aspiration pneumonia after emergency endotracheal intubation. Am J Emerg Med 2018;36:193-6.

16 Zehtabchi S, Sinert R, Baron BJ, et al. Does ethanol explain the acidosis commonly seen in ethanol-intoxicated patients? Clin Toxicol 2005;43:161-6.

17 Tenenbein M. Do you really need that emergency drug screen? Clin Toxicol 2009;47:286-91.

18 Hulse GK, Robertson SI, Tait RJ. Adolescent emergency department presentations with alcohol- or other drug-related problems in Perth, Western Australia. Addiction 2001;96:1059-67.

19 Romano E, Pollini RA. Patterns of drug use in fatal crashes. Addiction 2013;108:1428-38.

20 Mick I, Gross C, Lachnit A, et al. Alcohol-Induced impairment in adolescents admitted to inpatient treatment after heavy episodic drinking: effects of age and gender. J Stud Alcohol Drugs 2015;76:493-7.

21 Tõnisson M, Tillmann V, Kuudeberg A, et al. Plasma glucose, lactate, sodium, and potassium levels in children hospitalized with acute alcohol intoxication. Alcohol 2010;44:565-71. 
22 Shavit I, Konopnicki M, Winkler K, et al. Serum glucose and electrolyte levels in alcohol-intoxicated adolescents on admission to the emergency department: an unmatched case-control study. Eur $J$ Pediatr 2012:171:1397-400.

23 Lien D, Mader TJ. Survival from profound alcohol-related lactic acidosis. J Emerg Med 1999;17:841-6.

24 Shahin H, Gopinath SP, Robertson CS. Influence of alcohol on early Glasgow coma scale in head-injured patients. J Trauma 2010;69:1176-81. discussion 81.

25 Rundhaug NP, Moen KG, Skandsen T, et al. Moderate and severe traumatic brain injury: effect of blood alcohol concentration on Glasgow coma scale score and relation to computed tomography findings. J Neurosurg 2015;122:211-8.

26 Lange RT, Iverson GL, Brubacher JR, et al. Effect of blood alcohol level on Glasgow coma scale scores following traumatic brain injury. Brain Inj 2010;24:919-27.
27 Sperry JL, Gentilello LM, Minei JP, et al. Waiting for the patient to "sober up": Effect of alcohol intoxication on glasgow coma scale score of brain injured patients. J Trauma 2006;61:1305-11.

28 Stuke L, Diaz-Arrastia R, Gentilello LM, et al. Effect of alcohol on Glasgow coma scale in head-injured patients. Ann Surg 2007;245:651-5.

29 Moulton C, Pennycook AG. Relation between Glasgow coma score and cough reflex. Lancet 1994;343:1261-2.

30 Moulton C, Pennycook A, Makower R. Relation between Glasgow coma scale and the gag reflex. BMJ 1991;303:1240-1.

31 Adnet F, Baud F. Relation between Glasgow coma scale and aspiration pneumonia. Lancet 1996;348:123-4.

32 Vadeboncoeur TF, Davis DP, Ochs M, et al. The ability of paramedics to predict aspiration in patients undergoing prehospital rapid sequence intubation. J Emerg Med 2006;30:131-6. 